Sofie Remijsen*

\title{
Living by the Clock. The Introduction of Clock Time in the Greek World
}

\author{
https://doi.org/10.1515/klio-2020-0311
}

Summary: This paper discusses how the notion of clock time was introduced in the Greek world. On the basis of an analysis of the earliest (potential) references to hours and clocks in texts from the late fifth to the early third century BC in their historical context, and with reference to the earliest archaeologically attested clocks, it proposes a scenario for the conception and development of this conventional system. It offers a new interpretation of the problematic passage Herodotus 2.109 and argues that an hour-like unit was developed by late fifth century astronomers, under Babylonian influence, to denote the time in which a celestial body moves through a section of its diurnal circle. When this astronomical concept moved to the civic sphere in the second half of the fourth century, it changed from a scientific unit of duration to a civic unit for measuring the time of day. This shift probably took place in Athens, where the first references to hours appear in this period together with multiple experiments in clock making, as well as humorous reactions to the newfound sense of temporal precision. The paper will also show, however, that these first clocks did not yet tell seasonal hours - the type of hours that would eventually define Greco-Roman clock time - and still measured the lapse of time rather than enabling the location of moments in time. Greco-Roman clock time was only fully formed when it incorporated Egyptian notions of the hour in the Ptolemaic kingdom of the early third century BC.

Keywords: Clock Time, Hour, Clocks, Sundial

\section{Introduction}

Whereas the length of a day is defined by the rotation of the earth, any system to divide up the day into smaller chunks of time is conventional. People locate moments in time, for instance, by referring to handpicked positions of selected celestial bodies, or to human or animal behavior, such as the filling of the market square or a cock's crow. Clock time, which imposes a regular grid of temporal units of equal size on the day, is a particularly artificial system. Because the units

*Kontakt: Sofie Remijsen, E-Mail: s.m.j.remijsen@uva.nl

2 Open Access. (C) 2021 Sofie Remijsen, published by De Gruyter. (c) BY This work is licensed under the Creative Commons Attribution 4.0 International License. 
are not grounded in nature or social practice, it is necessary to use instruments, that is clocks, for orienting oneself on this abstract temporal map. The development of such a system for time location is, therefore, far from self-evident. This paper will examine how clock time was introduced in the Greek world.

The standard Greek unit to express clock time is the 'hour' or $̋$ p $\alpha$. This word already had a plethora of other meanings before it was used in this sense. It can also be translated as, for example, 'season', 'age' or 'time'. Therefore, examining the beginning of clock time in the Greek world means asking how the word $\omega \rho \alpha$ came to be used for telling the time of day. This is not the same as asking when $\omega$ $\rho \alpha$ came to denote 'hour'. A problem of most studies of the Greek hour is a lack of differentiation between the two different types of hour covered by this term. The equinoctial hour ( $\ddot{\omega} \rho \alpha$ ion $\mu \varepsilon \rho ı \eta$ ) represented $1 / 24^{\text {th }}$ of the time the earth needs to rotate around its axis, and therefore had the same length as

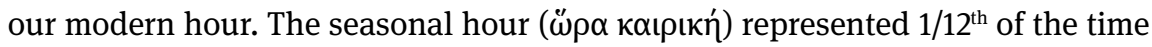
of daylight or night respectively; its length, consequently, varied according to the season. These often-noted differences in length are connected to differences in function. Seasonal hours are inherently a system for telling the time of day, i.e. clock time. Because the hours of the day are separated from the hours of the night, sunrise and sunset serve as fixed points from which the hours are counted (e.g. "at the second hour"). ${ }^{1}$ Equinoctial hours, on the other hand, can be counted from any moment during the day. If a fixed starting point is determined, they can be used for clock time, as we do today, but there is no starting point inherent to the system. The advantage of equinoctial hours is precisely their usefulness for measuring durations from any point in time (e.g. "after two hours"). The standard Greco-Roman clock time of the Hellenistic and Roman period was based on seasonal hours, although some astronomers used equinoctial hours. For the late Classical period, the situation has not yet been clarified. One issue this paper must therefore address is which of these two types of $\omega^{\prime} \rho \alpha$ was introduced first, a question that has received surprisingly little attention. ${ }^{2}$

1 The meaning of this phrase ( $\ddot{\rho} \rho \alpha$ with ordinal number) is the central issue discussed in Bilfinger 1888, the first systematic study of ancient hours and still the most substantial. He established that this could refer to a moment within a specific hour of the day, but it was mostly used to refer to the end of this block of time, as is the equivalent modern phrase "two o'clock".

2 Bilfinger 1888 observes that the idea of the hour as a point in time developed out of the hour as an interval (7), but he is dealing with the precise meaning of time notations of seasonal hours, and is not interested in the question of which type was first (74). Ginzel 1911, 308 assumed that the seasonal hours were first, and that the astronomers created the equinoctial hours in reaction to the unpractical nature of the former for scientific observations. Kubitschek 1928, 174-187, the last to devote a considerable section to hours in a chronological handbook, does not discuss the matter. Franciosi 1981, 141, 150 assumes that the seasonal hours were first, but thinks that they 
The article is only concerned with the introduction of clock time in the Greek world. It is important to note, however, that both equinoctial and seasonal hours had precursors in the East. In Egypt, seasonal hours were used at least from the second millennium BC. From the New Kingdom onwards, various types of timekeeping devices (tables of rising stars, water clocks and planar, L-shaped and sloping sundials), as well as astronomical representations including processions of personifications of the twelve hours of the day and of the night have been preserved. The context in which the need to identify specific moments in time first emerged here seems to have been a ritual one. ${ }^{3}$ As the last section of this paper will show, it is from Egypt that the concept of the seasonal hour would eventually be taken over in Greece.

Babylonian texts, on the other hand, use, at the latest from the seventh century BC onwards, an equinoctial unit of two modern hours, the beru, which was used to indicate the time that had passed relative to another moment, often sunrise or sunset. It developed from a unit of length - a distance that could be walked in roughly two modern hours - and it also became a unit of measurement of arcs, which are today measured in degrees. The beru was not a purely scientific unit, but there are relatively few attestations outside of scholarly texts, as short time was not very important in Babylonian culture. Although water clocks certainly existed, they were not widely used. ${ }^{4}$

The first section of this article offers a new interpretation of a problematic phrase in Herodotus, which is central to any discussion of the topic, as he speaks of a division of the day into twelve parts almost a century before any other references to the hour or to clocks can be found. The second section will then approach the introduction of clock time via the clocks themselves. The last section focuses on the earliest evidence for numbered hours, the quintessential feature of clock time, which coincided with a wave of innovations in clock-making technology.

too were originally used mostly in an astronomic context. Hannah 2009, 75 deems the question impossible; Bonnin 2015, 55 f. rightly remarks that the equinoctial hours are attested first. Sattler 2019, 172 leaves this question open.

3 A full catalogue of Egyptian clocks is compiled by Sarah Symons: the "Ancient Egyptian Astronomy Database" (https://aea.physics.mcmaster.ca/index.php/en/, accessed November 2019). The star clocks and sundials were examined in detail by Symons 1999 and Salmas 2013 and 2014. A more general, but less up-to-date discussion of Egyptian hours and timekeeping can be found in Clagett 1995, 48-106. The seasonal character of the hours is shown, for example, by the monthly changing scales of some instruments. Cf. Symons 1999, 136-159.

4 Meissner - von Soden 1965, 130 (bēru IV). For the most complete and recent discussion of units of short time, see Steele 2019, esp. 97 f., 100-121. Rochberg-Halton 1989 has argued that the Babylonians knew seasonal hours as well, but the evidence is insufficient to prove that they used these before the second century BC. Cf. Steele 2019, $116 \mathrm{f}$. 
On the basis of an in-depth analysis of these early written and material sources in their historical context, the article will propose a historical scenario for the conception and development of clock time in the Greek world. A follow-up article will explain the remarkably swift diffusion of this new system in the early Hellenistic period.

\section{Herodotus and the Astronomical Division of the Day in Classical Greece}

The earliest Greek source that could be taken to refer to hours is Herodotus 2.109:

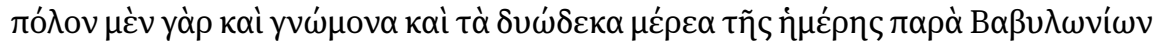

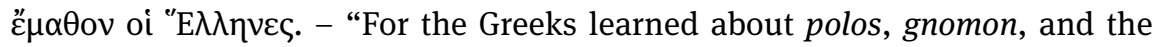
twelve parts of the day from the Babylonians." This passage comes up in a longer explanation about how the Greeks learned to measure land from the Egyptians, and thus seems to create a contrast between the measurement of space and that of time, which, according to the historian, the Greeks learned from the Egyptians and the Babylonians respectively. There is no contemporary evidence, either textual or archaeological, confirming that the Greeks indeed divided the day into twelve parts and used clocks as early as the fifth century BC. Therefore, this passage forms such a crux that it was once identified

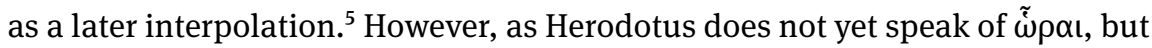
uses the generic term 'parts' ( $\left.\mu \varepsilon^{\prime} \rho \varepsilon \alpha\right)$, which suggests an early stage of development, that suggestion is not tenable. ${ }^{6}$ We should keep in mind that no texts by fifth century $\mathrm{BC}$ astronomers, the most likely context for parallels, have been preserved. Accepting that the passage is real, however, leads to the question of what exactly Herodotus meant. For a good understanding, we need to explain all three elements and to interpret them in the context of the knowledge available to the historian in the late fifth century BC. Establishing what are a gnomon and a polos sets the perimeters for the interpretation of what exactly is meant with "the twelve parts of the day".

5 Powell 1940.

6 Powell's arguments were immediately refuted by Robertson 1940. The standard commentary on book 2 of the Histories accepts the latter's views: Lloyd 1988, 34-36. 


\section{Gnomon}

The least problematic element of this sentence is the gnomon. Though later used as a pars pro toto for sundials, it is essentially a pointer casting a shade. According to later Roman sources, the use of the gnomon goes back to either Anaximander or his student Anaximenes in the sixth century BC, who set up a permanent gnomon in Sparta. The specific reference to Sparta, and the fact that they even give the name of this particular instrument (slightly varying, but always derived from $\sigma \kappa ı \theta \eta \eta \varepsilon ́(\omega)$ give this a ring of truth. ${ }^{7}$ A fragment of Oenopides, a contemporary of Herodotus, confirms that this instrument was at the time already wellknown among contemporary astronomers. ${ }^{8}$ The simplest usage of a gnomon is to trace the lengthening and shortening of the noon-time shadow of the pointer (i.e. the shortest shadow of the day) along a line on the ground, today referred to as a meridian line. In this way the days with the shortest and longest shadows can be identified as the solstices. The reason why archaic Greek cities wanted to determine the solstices with some degree of precision was calendrical: it enabled them to keep their lunar calendars more or less aligned with the solar year, so that seasonal festivals would be celebrated at their proper time. ${ }^{9}$ Although there is discussion about whether archaic gnomones were used to determine equinoxes, it is widely accepted that they were not used as clocks. ${ }^{10}$ This would require the

7 Plinius (NH 2.187; 1st cent. AD) calls Anaximenes' sundial the skiothericon and identifies it, anachronistically, as a clock (horologium). Diogenes Laertius (2.1.2; 3rd cent. AD) explains, on the basis of Favorinus (2nd cent. AD), that Anaximander set up this dial to observe the solstices and

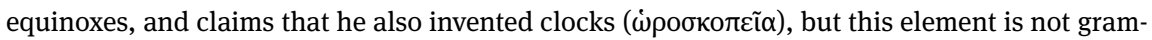
matically embedded in the previous clause, as if not from the same source. The better-informed and earlier Roman author Vitruvius (1st cent. BC) discusses the simple gnomon (Vitr. 1.6.6), but does not have sixth or fifth century BC scholars in his list of inventors of clocks (Vitr. 9.8.2, see infra).

8 Fr. 13 (= Procl. In Euclidem 283).

9 There seem to have been no fixed rules for intercalation in early Greek calendars (cf. Stern 2012, 38f.), so these instruments should be seen as tools offering guidance rather than hard and fast rules to the officials deciding whether a month should be intercalated. That the date for the Olympics was at the latest in the fifth century BC detached from the local Elean calendar (the games moved between local months) but fixed in relation to the solstice suggests that this was regarded as an astronomical event people across the Greek world would be able to identify. Cf. Miller 1975; Remijsen 2021, forthcoming.

10 E.g. Szabó - Maula 1982, 35f.; Hannah 2009, 68 f.; Bonnin 2015, 52. Dicks (1966, 30-35) observes that equinoxes, unlike solstices, are never mentioned in Greek texts until the late fifth century $\mathrm{BC}$, which points to a lack of interest, and explains that pinpointing the exact moment of an equinox requires not merely observation, but also calculations based on knowledge not available in this period. Hannah $(2009,69)$ has argued against this by showing that making a good approximation of the date of the equinox on the basis of shadow length lay well within the 
addition of a more elaborate dial tracing not only the length but also the direction of the shadow.

Herodotus might be right about the Babylonian origin of the instrument. The "Babylonian" astronomers of the sixth and fifth centuries BC operated in the context of the Achaemenid Empire, which bordered and closely interacted with the Greek world. Miletian philosophers such as Anaximander and Anaximenes may well have been inspired by their Eastern neighbors, as the seasonal variation in shadow length was already studied in Babylon several centuries before, which implies that they were using similar pointers. There is no evidence that the direction of the shadow was studied in Mesopotamia, so, as in early Greece, these pointers would not have functioned as clocks. ${ }^{11}$

\section{Polos}

Identifying what Herodotus meant with polos is the greater challenge. The

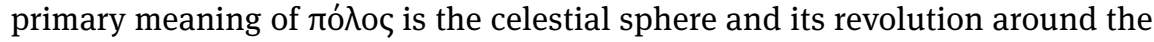
poles. Within the passage of Herodotus, the word is traditionally understood as a concave dial on which the shade of the gnomon was projected. ${ }^{12}$ This interpretation seems to be supported by the similar usage of both terms 600 years

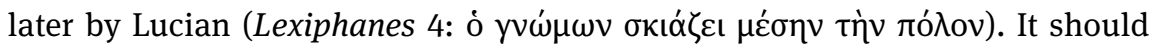
be noted, however, that the speaker of this line is the fictional Lexiphanes, a parody of an author so obsessed with Attic rare words that his style becomes tasteless and absurd. Lucian is, in other words, deliberately aiming for the awkward "casting a shadow in the middle of the celestial sphere" instead of for the more normal "on the dial". We have no positive evidence that referring to a dial as a polos was normal usage in the imperial period, let alone 600 years earlier. The archaeological evidence, moreover, leaves no doubt that the interpretation is anachronistic: concave sundials were not developed until more than a century after Herodotus. The alternative interpretation of the polos as a semi-circular planar dial sometimes given in reaction to this problem does not really solve it, as even these are not attested for at least half a century after

capabilities of the early users of the gnomon. Dicks' observation that the equinox was apparently not yet a day of interest in Archaic Greece remains valid, however.

11 See Steele 2013 for a discussion of these shadow length tables; Steele 2019, 120 for their use as a calendrical tool and not as clock.

12 E.g. Franciosi 1981, 147-150; Lloyd 1988, 34. Hannah 2009, 71 discusses the problems with this theory, but does not offer a clear alternative. 
Herodotus. ${ }^{13}$ The only way out of this impasse is to re-examine all references to poloi in the context of time-reckoning without a priori assumptions.

The only near-contemporary author that connects a polos with time-reckoning, and who therefore holds the key to understanding this passage by Herodotus, is Aristophanes. From his lost comedy the Gerytades, in which the main charac-

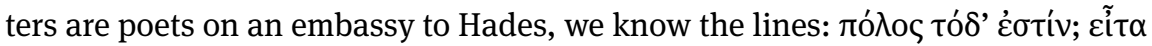

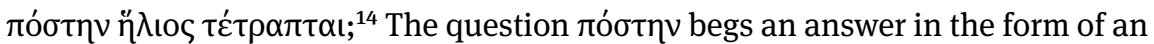
ordinal number. This fragment is preserved by Pollux, who identifies the polos as

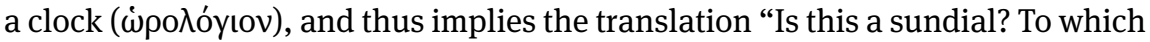
hour has the sun then turned?". But this is the interpretation of a contemporary of Lucian, who knew all about concave sundials, but had little knowledge about the historical realities of a world more than half a millennium before his own lifetime. As in the case of Lucian, this is not even representative for the meaning of polos in the imperial period, as Pollux was a lexicographer and Atticist, and perhaps

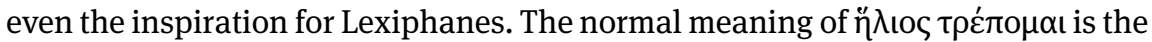
change of path of the sun at the solstice, which is hence called $\tau \rho \circ \pi \eta{ }^{15}$ There-

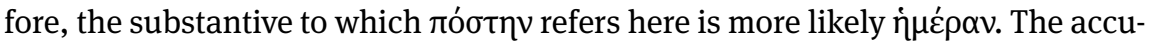
sative $\dot{\eta} \mu \varepsilon^{\prime} \rho \alpha v$ with an ordinal number and without preposition expresses "how long ('the $\mathrm{n}^{\text {th }}$ day') since". ${ }^{16}$ Within this passage, therefore, the polos is something on which one could see the date of the solstice: "How many days ago has the sun turned?" Why this was funny, escapes us, as the context of the fragment is lost. Aristophanes might be ridiculing the idea that anyone would want to use a polos, or would want to know the exact day of the solstice, or it might just be part of the build-up to a joke.

This new translation is compatible with an existing theory that identifies the polos with the so-called heliotropion which Meton - a contemporary of both Herodotus and Aristophanes - set up on the Pnyx in Athens. ${ }^{17}$ This identification is based on a comment by Achilles Tatius, an imperial-age commentator on Aratus, who mentions that Aristophanes talked about the polos in connection to

13 Schaldach 2006, 31-33 for the early history of sundials. For a planar dial as alternative, see e.g. Ginzel 1911, 306; Schaldach 2006, 4; Bonnin 2015, 51-54.

14 Fr. 163. For this play, see Farmer 2017, 197.

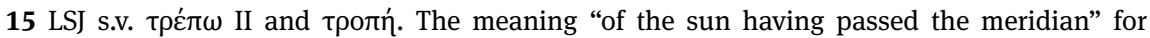
трє́ло $\mu \alpha$ เ is only based on Pollux' interpretation of this fragment. The other passage referred to for this particular meaning (Antigonus, Historiarum mirabilium collection 60) can be read as a reference to the solstice.

16 Van Emde Boas et al. 2019, 365-366 (§30.15 on the accusative of [duration of] time).

17 This device is mentioned by Philochorus FGH 328 (ca. 300 BC), Fr. 122 (from a scholion on Aristoph. Av. 997). Translated by N. F. Jones on the website of Brill's New Jacoby: http://dx.doi. org/10.1163/1873-5363_bnj_a328, accessed May 2020. E.g. Hannah 2009, 71. 


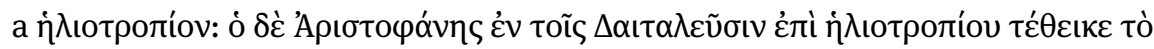

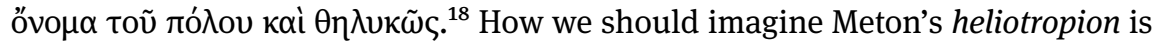
disputed: solutions range from various types of more or less monumental sundials to "a device aligned to a solstitial rising-point such that a part of it was illuminated only on the day of solstice"19.

The idea that the polos must be the same device as the heliotropion rests on shaky grounds, however. One problem is the location of both objects. Tatius includes a second fragment from Aristophanes, this time from his first play,

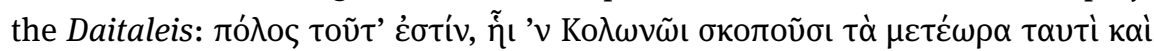

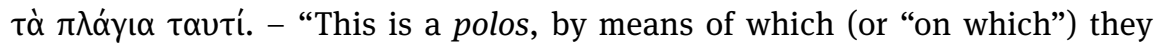
behold in Colonus those things in heaven and those around the celestial pole" (or "those things high in the sky and along the horizon"). ${ }^{20}$ So the polos stood at Colonus, whereas the heliotropion stood on the Pnyx. The second problem is the connection between the two. When Tatius explains that Aristophanes used

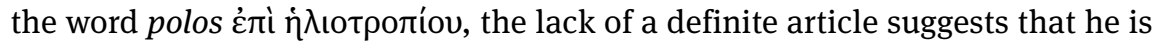
not talking about a specific monument; the phrase could just mean "concerning a solstice".

Although the identification with the heliotropion is not convincing, the work of Meton and Euktemon, the leading Athenian astronomers of the late 430s, offers the right historical context in which to interpret both passages about the polos. An otherwise unknown author named Callistratus states that Meton set up an astronomical anathema at Colonus, that is a 'dedication', something that was 'set up', often a monument in stone. ${ }^{21}$ Small-town Colonus is unlikely to have had two contemporary but unrelated astronomical objects; Aristophanes must be referring to the same thing. He certainly knew Meton, as he ridicules him in his "Birds".22 Herodotus can likewise have known about Meton. Even if many details about Herodotus' life remain hypothetical, he was clearly well-connected to Athens and possessed up-to-date knowledge on the city at least up to $430 .{ }^{23} \mathrm{By}$

18 Isag[oga] exc[erpta] 28.33-35: "Aristophanes in his Daitaleis in the context of a heliotropion/ solstice puts the word polos also in the feminine gender."

19 Bowen - Goldstein 1988, $72 \mathrm{f}$.

20 Not included in most fragment collections, cf. Franciosi 1981, 148f., n. 19. Preserved in: Ach. Tat. Isag. exc. 28.36-37.

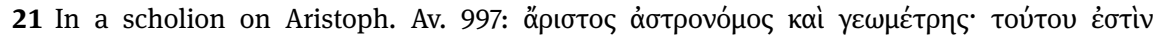

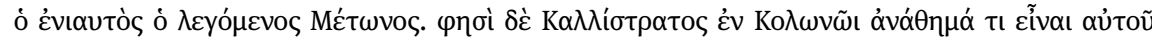

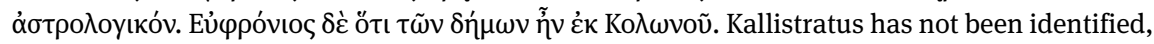
but the whole scholion is printed under Philochorus FGH 328 (ca. 300 BC), Fr. 122.

22 Av. 992-1010.

23 The traditional idea that Herodotus spent several years in Athens in the 440s is no longer taken for granted today, as very little concrete details about his life are known. Undisputed, how- 
this date, Meton was a public figure in Athens. As we just saw, he set up at least two public monuments. Together with his colleague Euktemon, he is said to have observed the summer solstice in $432 \mathrm{BC}$. ${ }^{24}$ They calculated a year length of 365 5/ 19 and proposed the so-called Metonic cycle for the intercalation of lunar months in the civic calendar. ${ }^{25}$ This possibly happened under Near Eastern influence, as a 19-year cycle was already in use at this point in the Persian Empire, and the contacts between Greek poleis and the Persian Empire were intense in this period. This again fits with Herodotus' image of Babylonian influence. ${ }^{26}$

The sparse evidence thus allows us to identify Aristophanes' polos with an astronomical monument set up by Meton at Colonus, which was connected explicitly but not exclusively to the solstices. His contemporary Herodotus does not use an article in his phrase, which implies he considered it a type rather than a unique monument. Unfortunately, none of this allows us to establish with certainty what type of object this astronomical monument was. The automatic assumption has thus far been that the polos must be an instrument for astronomical observation, ${ }^{27}$ but as this unknown instrument needs to be distinguishable from the gnomon and the heliotropion and to be realistic for the fifth century BC, this has led to an impasse. An instrument for observation is not the only option, however. I would like to propose an alternative hypothesis. The name polos makes sense if the monument did not measure, but represent the celestial sphere or its revolutions. The medium of a public monument suggests a wish to share knowledge with a broader public. Therefore, the simpler the representation the more likely it is. Aelian claims that Meton published his work on "stelae". ${ }^{28}$ This would fit well with an interpretation of the astronomical monument at Colonus as a stone inscription.

ever, are that he visited the city, given his detailed knowledge of Athenian topography (8.52-55), that in the later part of his life he was a citizen of Thurii (Aristot. Rhet. 3.9), which as a foundation initiated by Athens in the 440s had a large Athenian community, and that some parts of his "Histories" seem to specifically address an Athenian audience. He had up-to-date knowledge about Athens as late as 430 (9.73). References to his work by Athenian dramatists show that it was well known there. According to Plutarch, "On the malice of Herodotus" 862A, the Athenians even honored him with a large sum of money for his work. 785B suggests he was personally acquainted with Sophocles. Cf. Munson 2013, 4-13.

24 Ptol. Synt. I.1 205.21 (= Alm. 3.1). For the date of this solstice, see the Milesian parapegma, fr. 84 (edition in Lehoux 2005, 136-136).

25 Dicks 1970, $88 \mathrm{f}$.

26 Full discussion of the introduction of this cycle in Babylonia in Stern 2012, 102-123.

27 E.g. Ginzel 1911, 306; Hannah 2009, 71.

28 Ael. VH 10.7 
In the past, some scholars have explained Aelian's “stelae” as a parapegma: an astronomical (i.e. solar) and meteorological calendar. ${ }^{29}$ Although most of these calendars have been preserved in a literary form, the term is derived from their epigraphic form: a list of days with astronomical and meteorological information and with a hole for each day and a movable peg to locate the current position in the solar year. A list of 365 days indeed is a very simple way of representing the solar year, and thus the rotations of the celestial sphere. However, Lehoux has recently argued that parapegmata are a somewhat later phenomenon. His argument is convincing as far as the astrometeorological data go: the snippets of astronomical data attributed to Meton and/or Euktemon in later parapegmata do not allow for the reconstruction of a full astronomical and meteorological calendar by Meton and Euktemon. Lehoux suggests therefore that the steles (plural) of Meton would have contained nothing more than a list of season lengths and that the parapegma-tradition started at some point after Meton, when the tradition of astrometeorological literature (which preceded Meton) was combined with the peg-and-hole technology for tracking cycles (which is used for calendrical purposes in an inscription of the fifth century BC, is thus at least contemporary to Meton). Lehoux' terminus ante quem is the early first century BC, the date of the earliest extant example of an epigraphic astrometeorological parapegma, found at Miletus. There are no earlier fragments, but no substantial later fragments either, because parapegmata were rare inscriptions in the epigraphic cityscape, with minimal chances of preservation. This means that the terminus ante quem does not necessarily bring us close to the inception of the genre. ${ }^{30}$ Searching for occurrences of the term parapegma shows that it was in common use by the first century, but that the word may have been used in the meaning of an astronomical calendar as early as the fourth century. ${ }^{31}$ According to the current state of the evidence Meton knew the bare-boned-structure of the astronomical year and had access to the peg-and-hole technique in his own city. So he may very well have used this technology in an inscription showing the length of the solar year and the position of the solstices and equinoxes within it, without necessarily adding a lot of astrometeorological information from the literary tradition. Making information on the solar year public could only serve a purpose if the onlookers had

29 Dicks 1966, 39; Hannah 2001, 143-159.

30 Lehoux 2007, 22-26, 96. The earliest inscription with the peg-and-holes technology comes from the Kerameikos: IG II 2782.

31 The earliest attestation of the word parapegma may be found only one generation after Meton, in the writings of Democritus, according to the list of his works in Diog. Laert. 9.48 (Democritus T33), but this may well be a later title of his book on astronomy. In the 1st cent. BC, it is

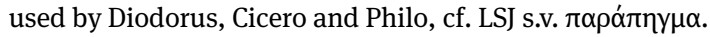


some way to orient themselves within the cycle. The peg-and-hole system was the logical way, as dates expressed with reference to the civil calendar were not an option, because the lunar calendar was not compatible with a solar calendar. The interpretation of polos as a simple astronomical calendar would certainly explain why Aristophanes has one of his characters ask how many days had passed since the solstice. ${ }^{32}$

\section{The Twelve Parts of the Day}

It follows from the above that neither the gnomon (a pointer) nor the polos (probably an epigraphic solar calendar) were used in the fifth century BC for measuring the time of day. But Herodotus does speak of a division of the day into twelve parts and associated this with the gnomon and the polos. Can we make sense of these twelve parts within the context of what we do know for certain about classical astronomy and without assuming there must have been clocks to measure them?

In the later fifth century, there was an increased interest in measuring the angles of celestial arcs. The earth's revolution around the sun creates the illusion that the sun describes a circular path in the course of the year. This apparent path of the sun is the zodiac, in the plane of the ecliptic. The rotation of the earth around its axis in the course of 24 hours creates the illusion of another circular path described by both the sun and the stars, their so-called diurnal circle. The diurnal circles of all celestial bodies run parallel to the celestial equator; only around the poles there is no apparent motion. These circles had been long known, but in the late fifth century astronomers started to measure them. Herodotus' close contemporary Oenopides, who is known as a geometer as well as an astronomer, was the first to measure the angle between the celestial equator and the zodiac as one fifteenth of a circle $\left(24^{\circ}\right) \cdot{ }^{33}$ Meton is likewise portrayed as a geometer of the sky in Aristophanes' "Birds", in which the main characters build a city in the sky. The fictionalized Meton proposes a circular city plan with streets

32 I found one other text in which polos could possibly translated similar as 'astral or solar calendar', from the period before parapegma became the established term: the famous Canopus decree from $238 \mathrm{BC}$, which documents an attempt to introduce a quadrennial leap day to align the Egyptian civil calendar better with the solar and astral year. OGIS 56 A, 46 = B, $46=$ C, 43 :

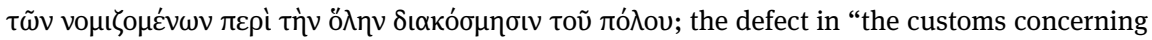
the whole regulation of the calendar" has been corrected. Austin 2006, 472 translates "the beliefs

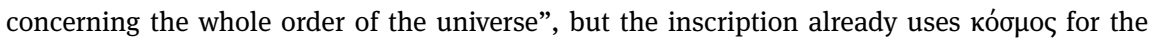
(ordered) universe (1. 41).

33 Szabó - Maula 1982, 120-122. For the best indicator of his lifespan (slightly younger than Anaxagoras), see Eudemus Fr. 133 and 145 (4th cent. BC). 
radiating out from the (floating) agora into the sky, and measures it out on stage. He is depicted, in other words, as dividing the celestial sphere into arcs. ${ }^{34}$

The Babylonians used a preexisting unit of duration, the beru, for measuring arcs. This is a logical choice, as the measurement of such an angle can never be separated from the time a celestial body needs to trace this part of its apparent path. The association between angles and time is also clear when Claudius Ptolemaeus, centuries later, used the system of 360 degrees or $\chi \rho o$ ó for celestial arcs. The Greeks of the late fifth century BC had no preexisting unit. In the search for a new standard, the equinox became interesting. Because the equinox, now known as ion $\mu \varepsilon \rho i ́ \alpha$, was the moment on which the day was exactly as long as the night, and the diurnal arc exactly as long as the nocturnal arc, it offered the standard with which to compare all other durations and celestial arcs. Euktemon is the first astronomer to whom dates of equinoxes are attributed. ${ }^{35}$ Democritus, who belongs to the next generation of scholars, is credited with calculations of the length of the day at the solstice. ${ }^{36}$

There are two ways of expressing the angle of an arc that can be found in what is left of astronomical works from the classical period. One way was to express the ratio between one part of the circle and the other. Aratus, following Eudoxus, describes the length of day and night at the solstice in Greece as a ratio of 5:3. ${ }^{37}$ Another way was to divide a celestial circle into "twelfth parts": a $\delta \omega \delta \varepsilon \kappa \alpha \tau \eta \mu o ́ p ı o v$ or $\zeta \omega \omega \delta$ เov does not only represent a specific sign of the zodiac, but also more generally an arc of $30^{\circ}$ in the sky, and also a duration..$^{38}$ Eudoxus in one fragment expressed the time between sunset and the visibility of the stars as "when the sun has sank half a zodion under the horizon"39. This suggests that Herodotus'

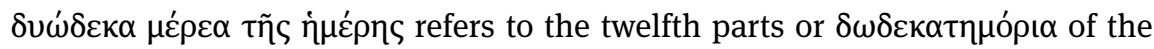

\footnotetext{
34 Av. 992-1010.

35 Geminus, Calendarium 100, 106 (ed. Aujac). Cf. Bowen - Goldstein 1988, 59.

36 Ptol. Phaseis 2.67.18. Cf. Sattler 2019, 176 f.
}

37 Arat. Phaen. 497-499. These verses are quoted by Hipparchus, In Arati et Eudoxi phaenomena commentariorum libri iii, 1.3.5-7. German translation in Szabó - Maula 1982, 23. The later author has to translate the ratio for his audience as 15 hours of the day and 9 hours of the night. Eudoxus himself also used ratios: see for example Fr. 67-68 (ed. Lasserre 1966).

38 For measuring angles, see Szabó - Maula 1982, esp. 199. The earliest source they quote is Autolycus (4th cent. BC), who also uses the half zodion (i.e. $1 / 24^{\text {th }}$ ), but no smaller divisions.

39 Fr. 128, ed. Lasserre 1966. The later author in whose text this is preserved (P. Par. 1 from the 2nd cent. BC) explains half zodion in an additional clause, mistakenly, as "a half hour". Interestingly, Eudoxus proves his statement with an experiment with a clepsydra: the same water that has flown out during the period of invisibility is reused when the stars have appeared and the period of half a zodion can be measured by means of the stars. The calendrical part of this same papyrus contains several references to equinoctial hours, but is not accepted as written by Eudoxus. 
diurnal circle. It should not be surprising that he talks about the diurnal circle rather than about the zodiac, as - as Plato also explains - this was the celestial movement that was the simplest to understand for non-specialists such as the historian. ${ }^{40}$ As a unit of duration, the zodion had the same length as the beru, which in turn suggests that Herodotus must be correct in attributing the origin of the twelve parts to the Babylonians. If my interpretation is correct, the contrast Herodotus wanted to create with the inclusion of one sentence on time in a section on land measurement is not a vague contrast between space and time, but one between measuring the land (surfaces) and measuring the sky (arcs).

\section{From Twelve Parts to $\tilde{\omega} \rho \alpha ı$}

The dodekatemoria or zodia were twice as long as the later $\tilde{\omega} p \alpha \mathrm{t}$; half zodia, however, were common subdivisions, and at some point they became the basic unit under a new, more general name. Pytheas of Marseille used the word ẅp $\alpha$ instead of a half zodion in a very similar context as the earlier astronomers. He uses $\tilde{\omega} \rho \alpha$ t to give the length of the longest day at various locations on his travels at the end of the fourth century, as a means to express their latitude. ${ }^{41}$ Unfortunately, his work (last quarter of the fourth century BC) is not preserved and is known only through fragments of authors who do not quote him literally, so,

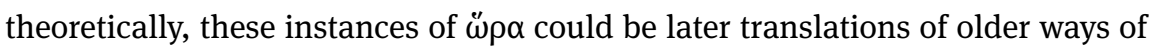
expressing these durations. Several arguments plead against this, however. First, information attributed to Pytheas about the length of the longest day for various locations is found in three different authors, who all express the length only in $\tilde{\omega}$ íc. Secondly, an astronomical papyrus from the early third century BC with derivative content show that the meaning of $\omega \rho \alpha$ as an equinoctial hour was well-established among scientists by that time. ${ }^{42}$ Lastly, the use of $\tilde{\omega} \rho \alpha$ appears even earlier in the civic sphere.

Fragments of Pytheas' contemporaries Theophrastus and Onesicritus, and of the somewhat older Aristotle, all speak of $\tilde{\omega} p \alpha$ in the sense of hours, that is as

40 Sattler 2019, 165. Esp. Plat. Tim. 39c.13: "Thus day and night came into being as the period

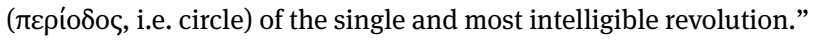

41 Pytheas Fr. 6b, 6c, 9a, 14. Interestingly, all authors referring to Pytheas (Strabo, Geminus and Kleomedes) use the later phrase $\dot{\omega} \rho \tilde{\omega} v$ ion $\mu \varepsilon \rho ı \tilde{\omega} v$ (equinoctial hours), and hence implicitly contrast them with seasonal hours, but these are not literal quotes and hence cannot be used as proof of Pytheas' usage. Strabo (Fr. 6) gets his information indirectly via Hipparchus (2nd cent.), Geminus (Fr. 9) used Pytheas directly, but the hours are mentioned in a paraphrased passage, before an actual quote from Pytheas, and Kleomedes (Fr. 14) does not identify his source.

42 P. Hibeh I 27 (cf. section 3). 
parts of the day that were of equal length and which could be added up to express duration. ${ }^{43}$ They all systematically use the plural $\tilde{\omega} \rho \alpha$, because they are using the term to quantify durations, and not yet for locating points in time. The earliest attestation of $\ddot{\omega} \rho \alpha$ is even earlier: it can, as Sattler has recently argued, be found in Plato's "Laws", his last dialogue dated to ca. 350 BC. Here, the philosopher expresses the duration of a daily assembly of a few selected women as "a third part of a $\omega \rho \alpha " .{ }^{44}$ This earliest reference must be very close to the first conceptualization of the hour, as there are no parallels in Plato's extensive earlier oeuvre.

In his "Laws", Plato sets out the regulations for the organization of his ideal society. This solidly places the first attestation of the hour in the civic sphere. The shift in scientific works from the precise term zodion to the utterly vague word $\omega \rho \alpha$, which could denote any period of time, likewise suggests influence by civic usage. Sattler hence argued that "the combination of natural philosophy with social concerns also brings with it some concern for regular sub-divisions of the day into hours" ${ }^{45}$. Whereas Sattler's objective was to show under which circumstances a pre-existing cultural practice became a concern for philosophers, the present paper aims to explain how this subdivision became a cultural practice in the first place. The next section will demonstrate that sundials had a vital role in the translation of an astronomical way of dividing the diurnal circle into a civic way of measuring time.

43 Theophr. Fr. 159 (cf. section 2). The connection to a water clock makes clear that he is talking about $\tilde{\omega} \rho \alpha t$ in the sense of hours. Onesicritus FGH 134, Fr. 10 (preserved in Latin via Pliny). Translation by Michael Whitby in Brill's New Jacoby: http://dx.doi.org/10.1163/1873-5363_bnj_a134, accessed May 2020. Onesicritus accompanied Alexander to India. Later he wrote that places in the far south of India had no shade around midday and concluded that the hours could therefore not be counted here. Aristot. Fr. 161 is a mathematical elaboration of "Iliad" 10.253 (ö $\sigma \tau \rho \alpha$

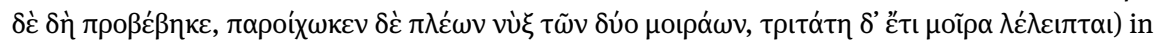
which the night is divided in various ways into parts. In the last section it is divided into twelve parts, which are subsequently referred to as hours. This fragment comes from a scholion, which makes its authenticity harder to ascertain.

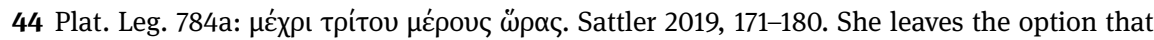
Hippocrates, Epidemics 4.1.12, which includes a reference to the third hour, dates from the first half of the 4th cent. The Epidemics comprises a collection of case notes of various physicians. A single passage is hard to date: although the majority of texts from the corpus date from the classical period, the corpus as such was probably compiled in early Hellenistic Alexandria. Hence it would be unsafe to accept this as the earliest evidence, especially because no other fourth century attestations refer to numbered hours.

45 Sattler 2019, 160. 


\section{The Emergence of Sundials as Clocks}

When were the first Greek instruments to tell the time of day designed? Schaldach has recently proposed a revised history of Greek sundials that starts in the fourth century BC with equatorial sundial models. ${ }^{46}$ This model consists of a thin marble plate with a dial and a gnomon on both sides. The plate is placed at an angle relative to the location of the instrument; the front dial is open to the elements, and the back dial is protected from the elements by the plate. In the summer, when the sun is positioned north of the equator, the shade is cast on the front dial; in the winter, the shade is cast on the back dial. Two examples of such a sundial have been dated by Schaldach to the fourth century BC: one found at the Amphiareion at Oropos and another at Olympia..$^{47}$ Both have hour lines so both can be identified as clocks. Only the sundial from Oropos can be independently dated: a terminus post quem is offered by the construction of the temple in the fourth century BC, and the epigraphist who published the inscription dated its letter style to the second half of the fourth century. ${ }^{48}$

Schaldach prefers a date in the third quarter of the fourth century for the Oropos sundial, that is still in the classical period, on the basis of two arguments. Firstly he follows the epigraphist who published the inscription in arguing that the name of the maker, Theophilos, was first engraved with a demotic, which was later replaced by his Athenian polis citizenship, and therefore must date from the time Oropos was under Athenian control (i.e. 335-322 BC). Hannah has re-examined the letter shapes and dates them more broadly between the midfourth and the mid-third century. He rightly observes that the mention of the Athenian citizenship is contemporaneous with the rest of the inscription, so it must be a patronymic and not a demotic that was erased. Therefore, the strongest argument in favor of an early date is invalidated. ${ }^{49}$ Schaldach's preference

46 3rd cent. BC: e.g. Ginzel 1911, 307, Gibbs 1976, 7 f.; 4th cent. BC: Schaldach 2004 and Herman - Sipsi - Schaldach 2015.

47 For all sundials I will refer to their Dialface ID in the open access "Ancient Sundials catalogue” published by Gerd Graßhoff with Topoi: http://repository.edition-topoi.org/collection/ BSDP, accessed May 2020. References to other catalogues, such as Gibbs 1976, Schaldach 2006 or Winter 2013 can be found here. Olympia: Dialface ID 736+737; Oropos: Dialface ID 319+718.

48 I.Oropos 359.

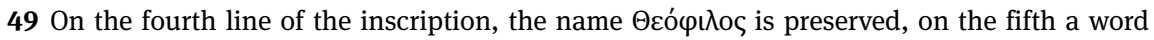
has been erased, and on the sixth we find 'AOnvoĩos, engraved in the same hand. The editor's suggestion that the erased fifth line may have contained an Attic deme explains Schaldach's date (2004, 441f.) between 350 and 320 BC. The normal onomastic pattern would, however, put a patronymic in between either a polis citizenship or a demotic, and would not combine the latter two. Cf. Schaldach 2004, 441 f.; Hannah 2009, 166f., n. 32. 
for the classical period rests, secondly, on his own identification of the Oropos sundial with the arachne, a sundial-type attributed by Vitruvius to Eudoxus. ${ }^{50}$ The name arachne suggests a (probably) two-dimensional dial with lines looking like a spider's web. Because this implies a combination of hour lines and day lines, the arachne must function as a clock. ${ }^{51}$ The identification of the arachne as the equatorial sundial must remain hypothetical, but is certainly possible. ${ }^{52}$ As Schaldach points out, the geometrical model developed by Eudoxus for the movements of the celestial bodies is a prerequisite for the development of equatorial sundial-clocks. Because the equatorial dials show a high level of complexity, Schaldach proposes that Eudoxus in fact further developed an older - not archaeologically attested - semi-circular sundial type. He assumes that the simpler device from Olympia, which has only hour lines, must be the older one, and that the day lines for establishing the solstices and equinoxes, which are partially present on the device from the Amphiareion at Oropos, must represent the addition by Eudoxus. ${ }^{53}$

Eudoxus is the oldest scholar in Vitruvius' list of sundial designers. Although Vitruvius is problematic as the sole basis for reconstructing the history of sundials - he is writing in the first century BC and says that others attributed the arachne to Apollonius of Perga, who lived 150 years after Eudoxus - the idea that Eudoxus was the first to design a sundial-clock is remarkably consistent with the literary evidence for hours. Eudoxus taught in Athens towards the end of the career of Plato, which is exactly when we find the first attestation of the hour and is known to have used half zodia himself. I agree, therefore, with Schaldach's identification of Eudoxus as a pioneer in clock-making, though not with his suggestion that the Olympia device must be even older.

We can distinguish between two elements in the evolution from a simple gnomon to the equatorial dials: on the one hand, the evolution from a linear scale to a circular dial, and, on the other, the evolution from a dial on a flat surface (the ground) to a dial placed on a plate at an angle relative to the local latitude. Schaldach places the latter evolution after the former, on account of its technological complexity. Once Greek astronomers were capable of calculating geographical latitude, a dial usable across the known world could be created by placing the

50 Vitr. 9.8.1.

51 Schaldach 2004, 443.

52 We do not know when the dial type known to Vitruvius in the 1st cent. $\mathrm{BC}$ as an arachne received this name. Bonnin 2015, $118 \mathrm{f}$. identifies the arachne with a different sundial model.

53 Herrmann - Sipsi - Schaldach 2015, 47. 
dial at an angle relative to the latitude. ${ }^{54}$ But whereas the change in angle turns the dial into an equatorial dial, the change from a linear to a semi-circular dial turns it into a sundial-clock. The changing shape of the dial is not characterized by technical complexity, but this does not automatically imply that it happened earlier. In fact, it required a greater conceptual leap. Putting the plate at an angle merely improved the gnonom's usability for its established purpose; creating a semi-circular dial on the other hand turned a tool for tracking annual cycles into a tool for tracking both the daily and the yearly courses of the sun.

We have to be careful not to confuse consequence for motive. Did sundials receive a semi-circular dial so that they could be used as a clock, or did sundials start to be used as clocks because they had received this dial? It would have been self-evident to the designer that a semi-circular dial could be used to trace the lapse of daytime, but there are indications that this potential use did not drive the design. We need to keep in mind that, in the second half of the fourth century, there was not yet a tradition of counting the hours from sunrise. Moreover, analysis of the early equatorial sundials shows that they are not particularly suited for such a use.

When looking solely at their usage as clocks, the design of the fourth century equatorial sundials is in fact awkward. Half of the year, you have to look at the back of the instrument to read it, which impedes easy consultation. In later centuries, when telling the time of day has become the primary use of sundials, equatorial models are therefore rare, and more readable models dominate. The early versions known from Oropos and Olympia are even more awkward than the few later examples, because the hour lines represent equinoctial hours: the lines divide the semi-circle at both sides of the plate into twelve equal parts of $15^{\circ}$ each. In the summer, therefore, the shade fell off the dial in the early and late hours and, in the winter, the shade never reached parts of the dial, because the apparent motion of the sun covers more than twelve equinoctial hours on a summer's day, and less than twelve on a winter's day, as the astronomers of these days knew well. ${ }^{55}$ In the days around the equinoxes, when the day does in fact count twelve equinoctial hours, the clock cannot be used either, because for part of the day, the shade is cast on neither dial. ${ }^{56}$ Because the shadow does not fall on a fixed

54 The theory that the earth was round already dates from the 5th cent. BC, but Eudoxus seems to have been the first to attempt to determine the latitude of a place mathematically. Cf. Szabó Maula 1982, $186 \mathrm{f}$; ; Heilen 2000, 61-63.

55 Hermann - Sipsi - Schaldach 2015, 39-43. The flaw is nicely illustrated by the figure of how an equatorial sundial for the latitude of Olympia should look like in Hermann - Sipsi - Schaldach 2015, 58: the summer side allows reading 14 hours, the winter side 10.

56 Hermann - Sipsi - Schaldach 2015, 41. 
point at sunrise or sunset on these sundials throughout the year, it is indeed very difficult to tell the time on these sundials.

To understand the creation of semi-circular dials, one should make a clear distinction between the interests of the designers and those of the eventual users of these instruments. The designers of fixed dials for a gnomon were people with an astronomical background, as is confirmed by the occurrence of many astronomers among Vitruvius' list of sundial designers. A Greek astronomer could, on the basis of the ratio between the length of any gnomon and that of its longest shade of the day, determine the approximate latitude of a place as well as the ratio of day and night, not only at that day, but at every day of the year, and on the basis of this knowledge place all the lines correctly. Astronomers did not need sundials for the scientific observation of time. Pytheas, for example, clearly did not use clocks to establish the length of the longest day at the various places he visited; he indeed could not have been at all these places during the summer solstice. Instead, he was able to extrapolate the length of the day on the basis of the length of the noon-time shadows in relation to the length of the gnomon. ${ }^{57}$

Why then did the designers introduce a circular dial instead of a simple line? This is easier to understand if we presume that the first decision was to place the dial no longer on the ground, but on a plate placed at an angle relative to the latitude. This plate, which had to be a square or rectangle for reasons of stability, was relatively empty, with just one line with markings for the solstices. Why not elaborate these markings? From the point of view of the designer, making a dial consisting of a semi-circle meant giving expression to his interest in both the daily and the yearly course of the sun. As solstice points are read at noon, the semi-circles representing the diurnal arc had to be subdivided at least in the middle, so why not subdivide them further in the established units of $30^{\circ}$, or in their common subdivision, the half zodion of $15^{\circ}$ ? If the first clock-maker was indeed Eudoxus, his choice of twelve rather than six subdivisions may even have been inspired by Egyptian planar dials. Semi-circular planar dials indicating twelve hours are attested here more than a millennium earlier. ${ }^{58}$ Eudoxus is said to have spent some time in Egypt in his biography by Diogenes Laertius. Although such stays in Egypt are a - sometimes unfounded - topos in philosopher biographies, it has been accepted as historical for Eudoxus, as Diogenes refers to two separate Hellenistic sources for this fact. ${ }^{59}$ But as Eudoxus is known to have used

57 E.g. Fr. 6c, where he gives both the number of hours and the shadow length at the solstice for Byzantion. Szabó - Maula 1982, 138; Heilen 2000, 63.

58 Gautschy 2017.

59 Diog. Laert. 8.8.86-87, 91. Cf. Lasserre 1966, 139-141. 
'half zodion' in a temporal sense (not $\tilde{\omega} \rho \alpha$ ), this link with Egypt is not essential for understanding the choice.

All known early Greek sundials and related instruments were set up either in public places (think of the skiothericon at Sparta or Meton's heliotropion on the Pnyx) or in sanctuaries (such as the Amphiareion or Olympia). This implies that the intended users of these instruments were citizens responsible for regulating both urban life and ritual. These users, not trained in astronomy, would not have known which units the subdivisions of the dial represented, but did understand that they represented the passing of daytime. At a loss for a better word, they saw the day divided in little 'chunks of time' or $\tilde{\omega} \rho \alpha ı$. In the civic sphere, tracing these chunks turned out to be useful. A passage in Aristophanes' Ekklesiazousai (651-652) jokingly tells us that, long before the first clock, Athenian socialites resorted to measuring their own shadow to know the right time for dinner parties. Once there were sundials that could function as clocks, people clearly embraced this enthusiastically. The devices from Oropos and Olympia document that the use as a clock quickly started to become more important than calendrical functions. Both devices diverge from the prototype that was developed, in all likelihood, by Eudoxus. The maker of the Oropos device paid less attention to solstice lines and more to hour lines than in his model. The line for the summer solstice, indeed, is left out, and instead the hour lines are extended to the middle of the circle, though engraved unsteadily in this sector because here it diverged from the model. ${ }^{60}$ The Olympia dial represents the next step: only the hour lines are drawn. As terminus ante quem for both devices I would suggest the 280 s, when, as the third section will show, the shift to seasonal hours had taken place.

Once people had discovered the convenience of an artificial division of the day into regular blocks, they soon felt the need for an alternative to the sundial on cloudy days. A large water-clock has likewise been excavated at the Amphiareion of Oropos, dated to the fourth century BC by early 20th century archaeologists. ${ }^{61}$ This is only a rough estimate on the basis of construction methods. The device is very similar to, however, and probably derives from the same designer as, another example found on the agora of nearby Athens. ${ }^{62}$ This one can be dated to the end of the fourth century on the basis of pottery produced around 320-310 BC and deposited above the overflow channel shortly after its construction. The scales

60 Schaldach 2004, 40.

61 Other sundials: Dialface ID 121, 254, 255, 256, 717. The most recent article on the water clock is Theodossiou et al. 2010.

62 Theodossiou et al. 2010, 163. 
used to read these devices are no longer attached to them. ${ }^{63}$ Basic water clocks such as these, however, can only have measured hours of equal length throughout the year. The Athens clock was changed in the course of the third century BC from an outflow to an inflow device. As this allows the operator to regulate the pressure of the inflow according to the season, this alteration allows for the measurement of hours of different lengths, and so can be connected to a shift from equinoctial to seasonal hours. ${ }^{64}$ But already in their original design, the water clocks document a burgeoning interest in knowing the time of day, as the stone tanks are - unlike the small ceramic clepsydrae from the classical period - big enough to be used for an entire day.

The center of the early experiments with clock time seems to have been Athens. The Oropos sundial was made by an Athenian and the two stone water clocks, one of them at Athens, seem to have been made by the same inventor. As Eudoxus taught at Athens and Plato is the first author to mention the hour, this may very well be the location of the first sundial-clock. It certainly was the place where most scientific progress was made in the second half of the fourth century. Of course, Athens was also the central node in the network of Greek scholars, so ideas spread quickly from here.

The Athenians themselves reacted to the new fashion for dividing the day into hours with a sense of humor. The leading comedian of the age, Menander, quickly picked up on it and immediately exaggerated the new fad for precise

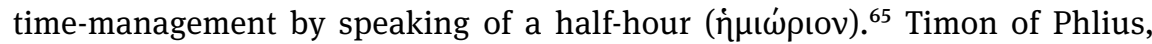
a slightly younger comic author who settled in Athens, wrote a parody epic, the Silloi, in which the reader meets various philosophers in Hades. Several fragments portray them as market vendors selling their ideas on the agora. Prodicus is ridiculed as a "money-grabbing teller of the hour" ( $\lambda \alpha \beta \alpha$ ópyopos

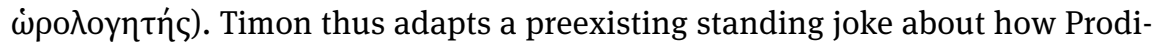
cus would charge more for longer lectures to a contemporary setting of an agora with a clock. ${ }^{66}$

63 Theodossiou et.al. 2010, 164-166 make the interesting suggestion that a mysterious marble plate with twelve horizontal lines found at the Amphiareion can in fact be identified as the scales. These lines would measure equinoctial hours. Assuming that the makers must have intended to measure seasonal hours, they postulate unnecessarily that there were different plates for different months, or, alternatively, more complex solutions.

64 See Camp - Armstrong 1977 for the Athenian device, and for a discussion of the Oropos device that remains more insightful than Theodossiou et al. 2010 with regards to the archeological aspects.

65 Fr. 1015. Word preserved without any context.

66 Fr. 792 (ed. Lloyd-Jones - Parsons 1983, 374), preserved in Athen. IX 406d-e. For Timon, the Silloi and the market scene and joke, see Clayman 2009, 1-3; $102 \mathrm{f}$. 
None of the fourth century sources combines $\ddot{p} \rho$ with an ordinal number, as is common in later references to seasonal hours. The earliest clocks all measured equinoctial hours. For sundials this made it difficult to have a clear point from which to start counting. But their fixed dial nevertheless created the illusion that each day should have twelve hours. Water clocks could be unplugged every morning at sunrise. It seems to have annoyed some users that the count than did not always end at the same number in the evening. This becomes clear in a longer fragment of Theophrastus, an author working in Athens in exactly the period that the large clepsydra was built on the agora and first used there. He refers to this clock with the word $y v \omega \dot{\mu} \mu \nu$, which at once distinguishes it from the small clepsydrae used in court and associates it with the contemporary use of equatorial sundials as clocks for a whole day. In his treatise "On Waters" he observes that water clocks measured the hours incorrectly in winter. This problem, he explains, was caused by the thickening of water in cold weather. ${ }^{67}$ This nonsensical explanation is interesting, because it shows that he - an intelligent scholar, but not an astronomer - assumed that every day should have twelve hours. He apparently did not understand that his everyday understanding of the hour clashed with the equinoctial scale of the device: thus, it seems that in his day, the conceptual distinction between the seasonal and equinoctial hour had not yet been made. The very small group of astronomers and geographers accustomed to their own unit of duration would have disagreed with the popular interpretation: the clocks were not wrong, the people just didn't understand how time worked. What we find in the last quarter of the fourth century, therefore, is only a rough, unfinished conceptualization of clock time that is suffering from the lack of a clear definition of the hour in its new, civic context. This problem would be solved when a new cluster of Greek thinkers formed in Egypt, where they found the idea of the seasonally changing hour fully formed - helping them to distinguish the two definitions of the hour and to accept both as 'correct'.

\section{Alexandria and the Acceptance of the Seasonal Hour}

It is in third century Ptolemaic Egypt that we can find for the first time the word

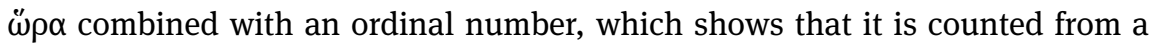

67 Theophr. Fr. $159=$ Athen. $2.42 b$. 
fixed point. The earliest attestation is preserved indirectly via Claudius Ptolemaeus (2nd century AD): the Alexandrian astronomer Timocharis is said to have observed the moon "at the end of the third hour of the night" on the 29th of January 283 BC. ${ }^{68}$ The distinction between day and night hours shows beyond a doubt that this is a seasonal hour. From the second quarter of the third century BC, we have a whole series of references to numbered hours, from the first to the twelfth, all from Ptolemaic Egypt. ${ }^{69}$ By itself, this clustering of evidence in Egypt is not enough to prove that the Greeks here were the first to make the conceptual distinction between seasonal and equinoctial hours, which enabled them to use hours to locate specific moments in time. The type of documentary evidence preserved in Egypt is not available for other parts of the ancient world and the Alexandrian authors were not writing for a strictly local readership. But Egypt was also the only place where Greeks could have encountered the system.

The key places where the Greeks could have encountered the Egyptian seasonal hour were the temples. The division of the day into twelve hours could theoretically have been applied to non-ritual contexts as well, but there is too little evidence for daily life in ancient Egypt to show whether it ever was. ${ }^{70}$ Those responsible for keeping time in the temple were astronomer-priests, who used clocks to identify the right time to perform certain rituals. ${ }^{71}$ This attention to the hour was certainly still alive in the early third century BC. It in fact continued to be a feature of Egyptian temple rituals after the Macedonian and later the Roman conquest. $^{72}$

68 Ptol. Synt.1,2.25-26: dated to the 29th of Hathyr in the 47th year of the first Calippic cycle. In the next sentence the time is rephrased as "three seasonal hours, or three and a third equinoctial hours before midnight”. This additional explanation is in all likelihood Ptolemy's, not Timocharis'. In another passage (1,2.310), Timocharis is mentioned again with an observation in the night from the 11th to the 12th October 272 BC, at the twelfth hour (Mesore 17-18, 13th year of Ptolemy II Philadelphus).

69 Authors: Posid[ippus], AB 124 = Anth. Gr. 5.183 (270-250 BC), Machon Fr. 9 (mid-3rd cent.). Callimachus Fr. 550 Pfeiffer is from the same period as Posidippus, but uses one hour in a durational sense. Documents: P. Hibeh I 110, P. Lond. VII 1973, P. Cair. Zen. II 59214, P. Cair. Zen. IV 59611 (all from the 250s). These will be discussed further in the follow-up article.

70 The best indication in this direction is offered by the archaeological context of a simple portable planar sundial recently excavated in the Valley of the Kings, which suggests that this object may have been used to keep track of the shifts of the men working on the tombs. The men did not work by the hour; documents from the same context show the existence of a morning and an afternoon shift. Whereas this sundial is very inaccurate when it comes to specific hours, for telling noon it is perfectly usable. Cf. Gautschy 2017.

71 Sauneron 1959.

72 SB XVIII 13118 D 6 and P. Tebt. II 599, 6 (2nd cent. AD, Tebtunis) refer to the Roman-age astronomer-priest as the horologos. SB I 5252, 20-21 (AD 65) mentions a festival in the local Isis 
There is good evidence that a dialogue between Greek astronomy and Egyptian temple knowledge started soon after the first Greek scientists had moved to Egypt. P.Hib. I 27, an astrometeorological calendar on papyrus, can be dated to shortly after $300 \mathrm{BC}$ on the basis of the date of the summer solstice. ${ }^{73}$ The author says in the preface that he had been living in the Saite nome (Lower Egypt) for five years and got his knowledge from a "wise man and friend". The lengths for the longest and shortest day and night are given in equinoctial hours and are consistent with the latitude of Sais. Written in Greek, the text follows many Greek conventions: it starts with an epistolary address and then provides information on the movements of the sun and stars on various days, the length of day and night in equinoctial hours and occasional meteorological information. In particular regarding the rising and setting of the stars, the calendar shows some similarities to what is known about the work of Eudoxus. Following the Greek astronomical tradition, the author has not measured the lengths of day and night but calculated them: four hours difference in half a year makes a shift of $4 / 180$ or $1 / 45$ hour each night. Although the scientific content has a Greek origin, the scholar is also taking over something important from the Egyptians: their calendar, which was more regular than any Greek equivalent. There are also multiple references to Egyptian religious feasts.

Just as the Greek astronomers could use the Egyptian calendar, they could also use their concept of the hour. In the temple, they could come across priests measuring the twelve hours of daylight or nighttime with various instruments. These demonstrated that the seasonal hour was not incompatible with clocks. Even the earliest known Egyptian waterclock (14th century BC) had monthly changing scales. ${ }^{74}$ This could create an awareness among Greek astronomers that the popular usage of the hour, which did not align with the scientific unit represented on the older Greek dials, did not have to be seen as "wrong”, but was in fact better suited for a system of time location. Contact with the Egyptians could thus speed up the creation of a distinction between equinoctial hours as a unit of duration and seasonal hours as clock time.

temple with a spondeion starting on the 8th hour of the 9th of Epeiph and ending on the 2nd hour of the 10th.

73 The standard edition P. Hibeh I 27 has a good commentary by Grenfell and Hunt. The date for the summer solstice is correct for 301-298 BC, which may be the date at which the teacher referred to in the prologue applied his knowledge to the local calendar at Sais. Because the calendar was off by one extra day every four years, it would have become useless within a few decades. The writing on the recto points to reuse no later than $240 \mathrm{BC}$.

74 WCO 1 in the Ancient Egyptian Astronomy Database by Symons, with further bibliography: https://aea.physics.mcmaster.ca/index.php/en/database/ars/ar1-type-menu/water-clock-amenhotep-iii, accessed May 2020. 
Egyptian clocks are far from accurate to modern standards, often making one hour longer than the next, but this was not an issue for the astronomer-priest, who was interested in the individual character of a period, not in its interchangeability with another one. ${ }^{75}$ Greek scientists, however, were used to think of the hour as a unit with a specific duration, so for them, these clocks did not suffice. They used their mathematical know-how to design new clocks for telling the time of day. In particular from the 280s on, there was a burst of inter-

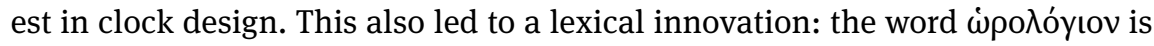
attested from the third century $\mathrm{BC}$ on. The lexical change from gnomon to horologion shows that the clock function in this period became the primary use of sundials. $^{76}$

Perhaps the most important step towards clocks accurately telling seasonal hours was the shift from planar sundials to concave sundials. On a planar dial, all hour lines are drawn in the same, south-facing plane. As the rising and setting point of the sun on the horizon changes throughout the seasons, planar dials do not catch the first and last shadows of the day on the same line throughout the same year. Whereas planar sundials track the position of the sun on the horizon, concave dials track the height of the sun. No matter at what point on the horizon the sun rises or sets, the concave dial catches the first and last sun of the day on the same east- and west-facing hour lines, running parallel to the horizon at the top of the curved side. Because the path of the shadow on a concave dial mirrors the apparent revolution of the sun, straight hour lines evenly spaced at $15^{\circ}$ distance on a concave dial correspond to seasonal hours.

According to Vitruvius, the astronomer Berosus was the first to hollow out the semicircle in which the shadow fell, and to incline it correctly. ${ }^{77}$ Berosus was born in the late fourth century $\mathrm{BC}$, and worked under the patronage of the Seleucids in the beginning of the third century. According to the Roman architect, he eventually established a school on the island of Cos, which was in the Ptolemaic sphere of influence. ${ }^{78}$ His adaptation made sundials much easier to read as clocks, but it is not clear whether this was his primary intention. After all, sundials had thus far been instruments to observe the solstices for astronomers such as him. The use

75 Salmas 2014, 466. See Hannah 2009, 85 f. for a parallel usage of imprecise sundials in e.g. medieval monasteries.

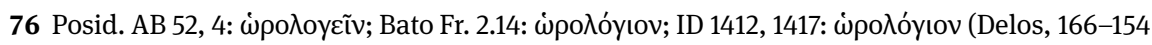
$\mathrm{BC})$.

77 Vitr. 9.8.1.

78 Vitr. 9.6.2. 
of "the hollow stone the Greeks call gnomon" for determining the solstices is also implied by the roughly contemporary author of P. Hibeh I $27 .^{79}$

After Berosus, Vitruvius mentions more inventors. Many names cannot be identified, but most of those that can worked in Alexandria in the reigns of Ptolemy II and Ptolemy III. Even Berosus, if he created his model during his time in Cos, could be connected to a broader wave of interest in clocks in Ptolemaic Egypt from the 280s onwards. Vitruvius mentions Aristarchus of Samos as the first to project the lines in a hemisphere. He was active in Alexandria as an astronomer by 280 BC and was taught by Straton of Lampsacus, who worked at the Alexandrian Museum in the first decade of the third century before returning to Athens. This teacher would have put Aristarchus in direct contact with ideas about time developed in late fourth century Athens. ${ }^{80}$ Another identifiable scholar on Vitruvius' list is Apollonius of Perga, who lived and worked in Alexandria under Ptolemy III and who has already been mentioned in connection with the arachne. After his succinct list of sundial designers, Vitruvius discusses at great length the complex water clock of Ctesibius, who worked in Alexandria in the time of Ptolemy II, and who accurately measured seasonal hours by adapting the flow of water to the time of the year. ${ }^{81}$ Whereas there is no way of assessing Vitruvius' laconic information on the inventors of sundials, the detail in his account of Ctesibius' work shows clearly that he based his information on the engineer's own writings.

Other sources confirm that Alexandria was indeed an important center of clock making. The Alexandrian Themistagoras is epigraphically attested as a dial maker on a sundial found in Herakleia ad Ladmum, in which he combines the principles of the equatorial type (the double dialface) with the new conical surfaces suited for seasonal hours. The letters are paleographically dated to the third century, probably to the reign of Ptolemy II. $^{82}$ The earliest explicit mention of a sundial as an instrument for reading hours also comes from Alexandria. The

79 The author explains that his teacher showed him the two courses of the sun with the help of such a gnomon: Hibeh I 27, Fr. A col. Ii, 11. 26-28. Theoretically, this expression could also refer to a water clock, but as the equinoctial hours are clearly mathematically determined and water clocks are useless for showing the annual course of the sun, this is very unlikely. It is realistic that he indeed determined the date of the solstices with the help of a sundial, but he cannot have used it for comparing the length of the night to that of the day with a precision of 1,3 minutes.

80 Folkerts 2006; Wildberg 2006.

81 Vitr. 9.8.2-15, esp. 6.

82 Dialface ID 149-150. Wörrle 1988, 434 thinks the letter style is most consistent with a date under Ptolemy II. Schaldach (in Hermann - Sipsi -Schaldach 2015, 62f.) comes to the same date, on the basis of the construction (a further development of the equatorial sundial type) and historical arguments (nearby Miletus was at the time in the Ptolemaic sphere of influence). 
court poet Posidippus (270-250 BC) wrote an epigram on the funerary monument of Timon "who set up this sundial to measure the hours", i.e. on his grave. ${ }^{83}$ It shows that by the mid-third century, clocks were already recognizable enough objects to be used in a symbolic manner.

Scientific progress in Alexandria clearly advanced further than in Greece. There, some tried to adapt the equatorial sundial to seasonal hours by experimentally adapting the line grid. On an equatorial sundial found at Phalara, for which the archaeological context suggests a date around 280-270 BC, the designer placed the hour lines on the summer side at intervals of $15,5^{\circ}$, and those on the winter side at intervals of $13,7^{\circ}$. This shows that he wanted to measure twelve hours on every day of the year, but lacked the mathematical understanding of the seasonal hour to do this correctly. ${ }^{84}$

Greek intellectuals in Alexandria, on the other hand, had by the 280s instruments to correctly measure seasonal hours, which they continued to improve in the second quarter of the century. While these clocks were spreading, clock time quickly moved out of the area of astronomy and dial-making. Before the middle of the third century, it was widely used even on the Ptolemaic countryside, and known across the eastern half of the Mediterranean, as well as in Rome. In a follow-up article, I will examine the dynamics behind this quick diffusion of clock time across such a wide range of social contexts and regions.

\section{Conclusion}

This paper aimed to explain how a conventional system of numbered hours was developed for telling the time of day in the Greek world. By examining in their historical contexts the few early references to a division of the day into hours, and by connecting them to recent insights in the study of ancient clocks, I have developed a logical scenario that traces the different steps in the inception of this concept, which led to an entirely new way of thinking about time in the Greco-Roman world.

The question of whether or not the Greeks knew clock time in the classical period hinges on the interpretation of one sentence by Herodotus, who claims

83 Posidippus AB 52. On this poem see Danielewicz 2005 and Gutzwiller 2005, 295-298. The habit of decorating funerary monuments with sundials is also archaeologically attested from the Hellenistic period onwards, cf. Dialface ID 52 (tomb of Theodotos, son of Menephron, 2nd cent. BC).

84 Dialface ID 738 + 809. Hermann - Sipsi - Schaldach 2015, 48-54. 
that "the Greeks learned about polos, gnomon, and the 12 parts of the day from the Babylonians". By showing which advances in classical astronomy would have been known among the educated elite in Athens, to which Herodotus was well-connected, I have argued that the problematic term polos is not a sundial or another instrument for the observation of the sun, as was previously assumed, but an epigraphic solar calendar, and that the twelve parts are not hours, but an astronomical unit dividing the diurnal circle into 'twelfth parts' or zodia.

The second section proposed a scenario for the conceptual leap from this equinoctial astronomical unit of duration to using hours in the civil sphere. I have attempted to show that the earliest sundials with a semi-circular dial were capable of being used as clocks, but that they were not designed with this use as their primary purpose. They were encountered in public places and used without understanding of the astronomical units they represented or a specific vocabulary to talk about them. In this context, around $350 \mathrm{BC}$, half zodia simply became "periods of time" or $\tilde{\omega} p \alpha t$. A preexisting interest in telling the time of day in urban and ritual contexts created a fashion for this new usage of sundials and led to new experiments in clock-making in the last quarter of the fourth century, in particular at Athens.

The civil use of the hour did not follow its original definition as an equinoctial unit. This caused the early clocks to be perceived as faulty by their users. This problem was solved, when the astronomers of Alexandria developed better clocks, fully embracing the Egyptian concept of the seasonal hour which they encountered in Egypt and differentiating it from their own astronomical units. By the 280s, the Greek concept of clock time had reached the form under which it spread across the entire Mediterranean.

Acknowledgements: I would like to thank Rita Gautschy and Sacha Stern for their useful comments on earlier drafts of this paper. The remaining mistakes in this article are, of course, my own.

\section{Bibliography}

Austin 2006: M. Austin, The Hellenistic World from Alexander to the Roman Conquest. A

Selection of Ancient Sources in Translation, Cambridge $2006^{2}$.

Bilfinger 1888: G. Bilfinger, Die antiken Stundenangaben, Stuttgart 1888.

Bonnin 2015: J. Bonnin, La mesure du temps dans l'Antiquité, Paris 2015.

Bowen - Goldstein 1988: A. C. Bowen - B. R. Goldstein, Meton of Athens and Astronomy in the Late Fifth Century B.C., in: E. Leichty - M. deJ. Ellis - P. Gerardi (eds.), A Scientific Humanist. Studies in Memory of Abraham Sachs, Philadelphia 1988, 39-81. 
Camp - Armstrong 1977: J. McK. Camp - J. E. Armstrong, Notes on a Water Clock in the Athenian Agora, Hesperia 46, 1977, 146-171.

Clagett 1995: M. Clagett, Ancient Egyptian Science, II: Calendars, Clocks and Astronomy, Philadelphia 1995.

Claymen 2009: D. L. Clayman, Timon of Phlius. Pyrrhonism into Poetry, Berlin - New York 2009.

Danielewicz 2005: J. Danielewicz, Posidippus Epigr. 52 Austin-Bastianini (P. Mil. Vogl. VIII 309, col. VIII 25-30), ZPE 151, 2005, 30-32.

Dicks 1966: D. R. Dicks, Solstices, Equinoxes and the Presocratics, JHS 86, 1966, 26-40.

Dicks 1970: D. R. Dicks, Early Greek Astronomy to Aristotle, Bristol 1970.

Farmer 2017: M. C. Farmer, Tragedy on the Comic Stage, Oxford 2017.

Folkerts 2006: M. Folkerts, s.v. Aristarchos [3], in: DNP online, 2006 (http://dx.doi. org/10.1163/1574-9347_dnp_e135290, accessed May 2020).

Franciosi 1981: F. Franciosi, Die zwölf Teile des Tages und die griechische Astronomie, AAntHung 29, 1981, 139-150.

Gautschy 2017: R. Gautschy, Astronomical Time versus Social Time. A Case Study from Ancient Egypt, Journal of Skyscape Archaeology 3, 2017, 217-223.

Gibbs 1976: S. L. Gibbs, Greek and Roman Sundials, New Haven - London 1976.

Ginzel 1911: F. K. Ginzel, Handbuch der mathematischen und technischen Chronologie, II: Das Zeitrechnungswesen der Völker, Leipzig 1911.

Gutzwiller 2005: K. Gutzwiller, The Literariness of the Milan Papyrus or 'What Difference a Book?', in: K. Gutzwiller (ed.), The New Posidippus. A Hellenistic Poetry Book, Oxford 2005, 287-319.

Hannah 2001: R. Hannah, From Orality to Literacy? The Case of the Parapegma, in: J. Watson (ed.), Speaking Volumes. Orality and Literacy in the Greek and Roman World, Leiden 2001, 139-159.

Hannah 2009: R. Hannah, Time in Antiquity, London - New York 2009.

Heilen 2000: S. Heilen, Eudoxos von Knidos und Pytheas von Massalia, in: W. Hübner (ed.), Geschichte der Mathematik und der Naturwissenschaften in der Antike, II: Geographie und verwandte Wissenschaften, Stuttgart 2000, 55-73.

Herrmann - Sipsi - Schaldach 2015: K. Herrmann - M. Sipsi - K. Schaldach, Frühe Arachnen über die Anfänge der Zeitmessung in Griechenland, AA 2015.1, 39-67.

Kubitschek 1928: W. Kubitschek, Grundriss der antiken Zeitrechnung, München 1928.

Laserre 1966: F. Laserre (ed.), Die Fragmente des Eudoxos von Knidos. Herausgegeben, übersetzt und kommentiert, Berlin 1966.

Lehoux 2005: D. Lehoux, The Parapegma Fragments from Miletus, ZPE 152, 2005, 125-140.

Lehoux 2007: D. Lehoux, Astronomy, Weather, and Calendars in the Ancient World.

Parapegmata and Related Texts in Classical and Near-Eastern Societies, Cambridge 2007.

Lloyd 1988: A. B. Lloyd, Herodotus, Book II. Commentary 99-182, Leiden 1988.

Lloyd-Jones - Parsons 1983: H. Lloyd-Jones - P. Parsons, Supplementum Hellenisticum, Berlin New York 1983.

Meissner - von Soden 1965: B. Meissner - W. von Soden, Akkadisches Handwörterbuch I, Wiesbaden 1965.

Munson 2013: R. V. Munson, Introduction, in: R. V. Munson (eds.), Herodotus, I: Herodotus and the Narrative of the Past (Oxford Readings in Classical Studies), Oxford 2013, 1-28.

Powell 1940: J. E. Powell, Greek Timekeeping, CR 54, 1940, 69-70.

Robertson 1940: D. S. Robertson, The Evidence for Greek Timekeeping, CR 54, 1940, 180-182. 
Rochberg-Halton 1989: F. Rochberg-Halton, Babylonian Seasonal Hours, Centaurus 32, 1989, 146-170.

Salmas 2013: A.-C. Salmas, La mesure du temps de la journée (I). Modules et fonctionnement des premières horloges à ombre, BIAO 113, 2013, 353-380.

Salmas 2014: A.-C. Salmas, La mesure du temps de la journée (II). Modules et fonctionnement des horloges à ombre tardives et des cadrans solaires, BIAO 114, 2014, 419-466.

Sattler 2019: B. Sattler, Cosmology and Ideal Society. The Division of the Day into Hours in Plato's Laws, in: K. Miller - S. Symons (eds.), Down to the Hour. Short Time in the Ancient Mediterranean and the Near East, Leiden - Boston 2019, 158-183.

Sauneron 1959: S. Sauneron, Le prètre astronome du temple d’Esna, Kêmi 15, 1959, 36-41.

Schaldach 2004: K. Schaldach, The Arachne of the Amphiareion and the Origin of Gnomotics in Greece, JHA 35, 2004, 435-445.

Schaldach 2006: K. Schaldach, Die antiken Sonnenuhren Griechenlands. Festland und Peloponnes, Frankfurt a. M. 2006.

Steele 2013: J. Steele, Shadow-Length Schemes in Babylonian Astronomy, SCIAMVS 14, 2013, 3-39.

Steele 2019: J. Steele, Short Time in Mesopotamia, in: K. J. Miller - S. Symons (eds.), Down to the Hour. Short Time in the Ancient Mediterranean and the Near East, Leiden - Boston 2019, 90-124.

Stern 2012: S. Stern, Calendars in Antiquity. Empires, States \& Societies, Oxford 2012.

Symons 1999: S. Symons, Ancient Egyptian Astronomy. Timekeeping and Cosmography in the New Kingdom, Dissertation University of Leicester 1999 (https://ra.le.ac.uk/ handle/2381/8546, accessed May 2020).

Szabó - Maula 1982: Á. Szabó - E. Maula, ENKLIMA. Untersuchungen zur Frühgeschichte der griechischen Astronomie, Geographie und der Sehnentafeln, Athens 1982.

Theodossiou et al. 2010: E. Theodossiou - M. Katsiotis - V. N. Manimanis - P. Mantarakis, The Large Built Water Clock of Amphiaraeion, Mediterranean Archaeology and Archaeometry 10, 2010, 159-167.

Van Emde Boas 2019: E. van Emde Boas et al., The Cambridge Grammar of Ancient Greek, Cambridge 2019.

Wildberg 2006: C. Wildberg, s.v. Straton [2], in: DNP online, 2006 (http://dx.doi. org/10.1163/1574-9347_dnp_e1123960, accessed May 2020).

Winter 2013: E. Winter, Zeitzeichen. Zur Entwicklung und Verwendung antiker Zeitmesser I-II, Berlin - Boston 2013.

Wörrle 1988: M. Wörrle, Inschriften von Herakleia am Latmos, I: Antiochos III., Zeuxis und Herakleia, Chiron 18, 1988, 421-476. 